\title{
Ilustradoras gráficas y viñetistas: su perspectiva en Instagram*
}

\author{
Trinidad NÚÑEZ DOMÍNGUEZ** \\ Teresa VERA***
}

\begin{abstract}
Resumen
Las viñetas firmadas por mujeres han estado prácticamente ausentes de la prensa diaria, aunque han tenido acceso a algunos semanarios o revistas. Las ilustradoras gráficas actuales optan por romper el techo de cristal valiéndose de Facebook o Instagram para participar en el circuito de la opinión pública. En este estudio se identifican a aquellas que hacen humor en España. Se ha manejado un corpus de ciento diez viñetas relativas a once ilustradoras gráficas. Como método se emplea el análisis de contenido, aplicándose una ficha de análisis a cada una de las viñetas. Ello permite valorar los ejes temáticos que definen sus obras y que comparten en Instagram. Los resultados demuestran que los asuntos político-sociales o laborales se convierten en relevantes. Así pues, se rompe el prejuicio sexista que dictamina que las mujeres no participan de la denominada información dura a través del humor gráfico.
\end{abstract}

Palabras clave: Ilustradoras, Humor gráfico, Instagram, Feminismo.

\footnotetext{
* Recibido el 29 febrero 2020, aceptado el 23 junio 2021.

** Profesora Titular de la Universidad de Sevilla, Sevilla, España. Investigadora del Proyecto I+D del Ministerio de Economía, Industria y Competitividad del Gobierno de España que se denomina Produsage juvenil en las redes sociales y manifestaciones de las desigualdades de género: nuevas formas de violencia. FEM2017-83302-C3-2-P.mtnunez@us.es/ https://orcid.org/0000-0002-1576-7402

*** Profesora Titular de la Universidad de Málaga, Málaga, España. Co-responsable del Proyecto I+D del Ministerio de Economía, Industria y Competitividad del Gobierno de España que se denomina Produsage juvenil en las redes sociales y manifestaciones de las desigualdades de género: nuevas formas de violencia. FEM2017-83302-C3-2-P. teresavera@uma.es / https://orcid.org/0000-0002-3089-4469
} 
Female Graphic Illustrators and Comic Strip Artists: Their Perspective on Instagram

\begin{abstract}
Comic strips signed by women have been practically absent from the daily press, although they have had access to certain magazines or weekly publications. Current female graphic illustrators have opted to break the glass ceiling by using Facebook or Instagram to participate in public debates. This study identifies female artists who work with humor in Spain. A corpus of one hundred and ten strips from eleven female graphic illustrators was examined. A content analysis method is used, by applying an analysis label to each strip. This allowed evaluating the thematic lines that define their work, which they share on Instagram. The results show that sociopolitical or work-related subjects are relevant. Thus, these artists challenge the sexist prejudice that limits women's participation in so-called hard information through graphic humor.
\end{abstract}

Keywords: Female illustrators, Graphic Humor, Instagram, Feminism. 


\section{Introducción}

Cuando se estudian precedentes teóricos y aplicados sobre el humor gráfico y los estudios de género, constatamos insuficientes trabajos de investigación al respecto. Los tipos de estudios encontrados se dividen en tres: a) aquellos que analizan la representación de las mujeres y del feminismo en la prensa, como el que se observa en el texto de Segado Boj (2009); b) los que se centran en las propias ilustradoras, en su trayectoria profesional y en el análisis específico de sus obras, tal como presenta el trabajo de Juszko (2000) sobre ilustradoras y viñetistas argentinas. Finalmente, c) un análisis sobre las mujeres creadoras que enfocan a las mujeres y a los asuntos que le preocupan. Es decir, se personifican las creaciones para valorar lo que dicen y cómo lo dicen. Así lo hace Valero Garcés (2005) analizando a las "mujeres superadas" de Maitena o a la "despeinada Magola" que surge de la pluma de la ilustradora colombiana Adriana Mosquera (Nani). En la mayoría de ocasiones el análisis se circunscribe a la prensa impresa (diarios, revistas, semanarios) aunque ya se empiezan a incluir el análisis de las redes sociales, tal y como presenta Ballesteros Doncel (2016), quien realiza un estudio sobre el humor que se transmite a través de mensajes de WhatsApp poniéndose el foco de análisis en el contenido concreto de esos mensajes.

Estos precedentes son considerados como un interesante punto de partida que complementar y ayudan a perfilar el centro de atención de este trabajo. Así, se parte del presupuesto de considerar la trascendencia del humor gráfico en la re-construcción de la realidad social y se toma como foco central el análisis de la producción gráfica de viñetistas e ilustradoras españolas actuales que usan las redes sociales para proyectar su visión del mundo en la esfera pública y provocar opiniones al respecto. No en vano es en la cuarta ola del feminismo donde se potencian estratégicamente el uso de las redes sociales y de los medios digitales, tal como han estudiado Araüna, Willen y Tortajada (2019) y Martínez (2019). Por lo tanto, se quiere reflexionar sobre el contenido de las viñetas reconociendo y visibilizando a sus autoras que, a su vez, son conscientes del alcance de sus mensajes y de las posibilidades del activismo en red.

Con la realización de este estudio queremos conocer quiénes son las mujeres que hacen humor gráfico en España actualmente para, una vez identificadas, valorar los ejes temáticos que definen sus obras y que comparten a través del perfil de Instagram. A través del método del análisis del contenido podremos evaluar, también, si rompen prejuicios sexistas alejándose de informaciones denominadas blandas.

El estudio se ancla en aspectos teórico-reflexivos relacionados con cuatro ejes: la visión psicosocial del humor, el humor gráfico, las mujeres y el humor gráfico, y un breve apunte sobre Instagram, como red social en progresión.

\section{La visión psicosocial del humor}

Siguiendo al Diccionario de la Real Academia de la Lengua Española, el humor supone un "modo de representar la realidad" (2000:1240). De esta manera, es posible afirmar que el humor se utiliza para valorar u ofrecer una opinión resultando un recurso potente para movilizar ideas tanto de personas como de instituciones. Tal como afirma Ballesteros Doncel, "puede mostrar malestares estructurales" (2016:34). También es una forma de mirar el mundo y comunicarlo, y como Monje (2007), sostenemos que el humor es una manera creativa de comunicar una visión del mundo.

Interesantes son los trabajos de Jáuregui (2007) quien define el humor como cualquier estímulo que pueda provocar la reacción psico-fisiológica de la risa (juegos, bromas, chistes, viñetas, situaciones embarazosas, incongruencias, inocentadas, cosquillas...). El autor señala la diferencia entre la risa como respuesta refleja (por ejemplo, en las cosquillas) de la risa como respuesta emocional a una idea o hecho. A la vez, define el sentido del humor como la capacidad de experimentar y/o estimular esta reacción. Así, el sentido del humor permite evaluar problemas comunes desde la crítica y la flexibilidad mental, lo cual hace que se puedan gestionar de una manera adecuada dichos problemas reportando claros beneficios biopsicosociales (Núñez

\footnotetext{
1 La ilustradora gráfica Maitena escribió el libro "Mujeres superadas" editado en 2002. En pocos meses logró vender más de 35.000 ejemplares.
} 
Domínguez, 2015). Es conocido que la risa, como una de esas expresiones del humor, consigue activar el sistema respiratorio, mejorar el ritmo cardíaco o ayudar a relajar los músculos. Así mismo, permite liberar tensiones emocionales. Por ese motivo se ha venido uniendo el sentido del humor y la salud. Y así lo encontramos representado en la literatura: desde Mark Twain (1876) a la reconocida y multipremiada poeta española Gloria Fuertes como claros exponentes: "el viejo soltó una alegre y ruidosa carcajada, hizo sacudirse convulsivamente todas las partes de su anatomía, y acabó diciendo que risas así eran mejor que dinero en el bolsillo, porque disminuían la cuenta del médico como ninguna otra cosa" (Twain, 2005:cap. XXX).

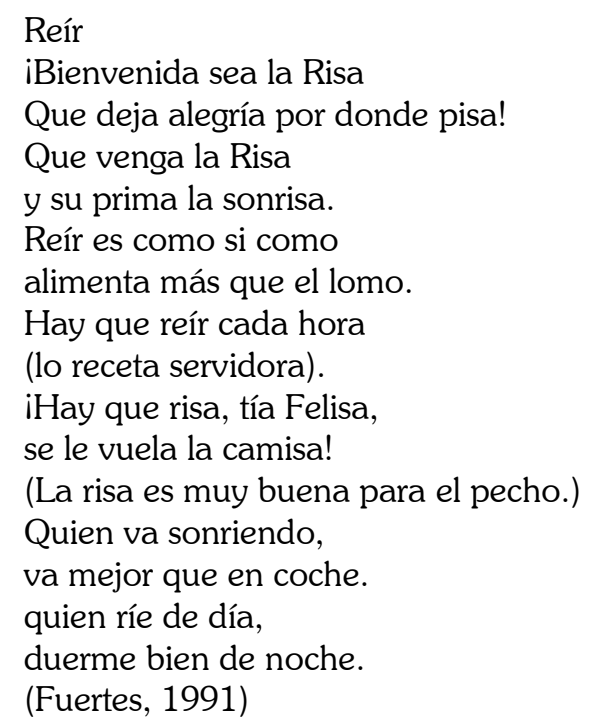

De la misma manera, el humor favorece las relaciones interpersonales en la medida que las hace más cómodas o flexibles y facilita también las relaciones sociales porque contribuye a reducir distancias psicológicas entre grupos. Como afirma Jáuregui, "permite atraer la atención del público, reducir distancias, estimular la memoria y suavizar el impacto negativo de mensajes problemáticos" (2007:147). El viñetista Jaume Capdevila considera que la risa se convierte en un elemento de cohesión grupal, argumentando que "lo cómico no se saborea en solitario. Necesita un eco" (2010:8).

Se lleva estudiando décadas las bases psicológicas que sostienen y explican el humor. Autores como Flügel (1954) o como Carretero Dios, Pérez Meléndez y Buela Casal (2006) han formulado ese anclaje psicológico a través de diferentes teorías explicativas. Puede hablarse de, al menos, tres: a) Teoría de la superioridad; b) Teoría del alivio y del control y c) Teoría de la incongruencia. La primera explica ese humor que incorpora elementos de desdén sobre personas o grupos de personas. Está al servicio de las actitudes discriminatorias sirviendo como factor cohesionador de los propios grupos dominantes. La segunda destaca que el humor contiene una parte emocional que facilita la descarga de tensión útil para salvar situaciones comprometidas, como sería en el caso de que existiera censura institucional (por parte de gobiernos o líneas editoriales) o de carácter personal. Esta teoría incorpora la transgresión como elemento polarizador que permite quebrantar normas o códigos socialmente impuestos. Un ejemplo de la teoría del alivio y del control lo encontramos en la propia línea de trabajo del semanario español La Codorniź que, como no podía ser de otra manera, vivió más de un cierre temporal por el contenido y las formas de sus viñetas. Una de las últimas acciones de la censura se produce del 15 de junio al 21 de septiembre de 1975 y el tema tratado fue, precisamente, la Universidad. La tercera teoría explica que el humor es capaz de convertirse en un potente estímulo para la imaginación y el sentido crítico ciudadano. Para ello

\footnotetext{
2 Nacido en junio de 1941, dos años después del fin de la Guerra Civil española, de la mano y pluma de Miguel Mihura Santos. Cierra su edición de manera definitiva en diciembre de 1978, año en que se promulga la actual Constitución española y con la que se formaliza el paso de España a la democracia. Siempre será recordada como "la revista de humor y optimismo". Empezó con una tirada de 35.000 ejemplares y con un precio de venta de 50 céntimos de peseta. Se consolida con Álvaro de Laiglesia, llegando a lanzar tiradas de 80.000 ejemplares.
} 
exige inversión de esfuerzo mental que permita unir, transformar y recrear la información que se recibe. Citamos, de nuevo, al semanario La Codorniz porque sus viñetas y reflexiones no solo son capaces de sortear situaciones censurables por el establishment sino que se convierte en una auténtica provocación tal como anuncia su portada: "la revista más audaz para el lector más inteligente". En estos momentos es el semanario El Jueves quien ha tomado el relevo (Barrero, 2014). Años antes, en plena transición política española, ocupó ese espacio reflexivo el semanario Hermano Lobo. En él ya colaboraban tanto el periodista Antonio Fraguas (Forges) como un joven Andrés Rábago ${ }^{3}$ (El Roto), dando idea del humor negro que luego iba a consolidar.

\section{El humor gráfico y las mujeres}

Participamos de las reflexiones de Capdevila (2010) para quien el humor gráfico es un medio de transmisión de ideas. En general se entiende que se trata de una forma de poner de relieve un tema puntual desde la 'mirada' de quien lo firma. Esto nos hace considerarlo más artículo de opinión que de información en su sentido más aséptico. De hecho, autores como Guillamet (1988) ya señalaban que en la prensa no solo se debe hablar de informadores sino de informadores gráficos, periodistas gráficos donde se incluyen fotógrafos y dibujantes porque "Todo es información... El espacio del dibujante habitual o una tira cómica pueden decir tantas cosas de interés como una crónica política convencional" (Guillamet, 1988:57).

En el análisis de las implicaciones psicosociales que tiene el humor gráfico, encontramos diferentes teorías explicativas. Con la selección o exclusión de determinadas informaciones, las viñetas impulsan el conocimiento al que se accede. Así lo considera la Teoría de la agenda setting (Cohen, 1963; McCombs y Shaw, 1993). Las viñetas seleccionan y re-construyen el universo de hechos y acontecimientos sociales a los que prestar atención. También la Teoría de indicadores culturales (Gerbner, 1998), aunque inicialmente se presenta específicamente unida al medio televisión, permite extrapolar su sentido afirmando que, a través de las viñetas, se cultiva una forma de entender el mundo, asentando creencias, representaciones mentales o actitudes.

Las viñetas representan el poder sintético de la retórica (Núñez Domínguez, 2015), logrando zamarrear emociones y obteniendo gran poder persuasivo por ello. Trabajos como los coordinados por Laguna Platero, Meléndez Malavé y Barrero (2010) dan buena cuenta de ello.

Teniendo en consideración que tanto para la Teoría de la Agenda como para la del Cultivo antes mencionadas, quienes hacen opinión se convierten en referentes sociales, puede considerarse oportuno realizar una serie de preguntas que permitan abrir el paso a otros análisis: ¿Las mujeres son generadoras de opinión? Y si lo son ¿en qué medios están presentes?, y consecuentemente, ¿generan opinión a través de viñetas o de textos?, ¿tienen, en definitiva, capacidad de agencia en la esfera pública?

Un estudio elaborado por Núñez Domínguez (2011) ya pudo concluir que las mujeres no generan opinión en los medios, dándose una preocupante carencia nominal que exponemos en cifras: En la radio un 17,16\% de mujeres hacen opinión; en la prensa diaria un 8,9\% (si es temática, un $3,2 \%$ y si es generalista, un $14,5 \%$ ). En la televisión, un $30 \%$. Y las mujeres no son agentes activos del humor en la prensa diaria. Así que, en los medios de comunicación, como ocurre en otros sectores profesionales, las mujeres no tienen toda "la voz" que les corresponde por formación y competencias. Participamos de las contundentes e irónicas palabras de Juszko (2000:25) cuando afirma: "Parece que el humor nació machito y fue hijo único por largo tiempo sin que a las mujeres, ni siquiera a las feministas, se les ocurriera romper ese unicato". Entendemos que la clave está en la dificultad para romper el techo de cristal en este ámbito profesional.

La escasa presencia se puede unir al tipo de informaciones que las mujeres hacen. Fagoaga (2004) entiende que existe una división sexual de la información de tal manera que se reconoce como información blanda aquella que da cobertura a aspectos sociales y culturales, a estilos de vida. Temas de entretenimiento de los que, sistemáticamente, se han ido ocupando las periodistas. Frente a ella está la denominada información dura (hardnews) que pone el foco en acontecimientos

\footnotetext{
3 Dibujante satírico y escritor que ha obtenido el Premio Nacional de Ilustración en 2012 y la Medalla de Oro al Mérito de las Bellas Artes en 2017, entre otros reconocimientos.
} 
vinculados a lo político y lo económico, vividos con gran significación para la vida ciudadana y de la que habitualmente se han ido encargando los periodistas. Así pues, los temas políticos o económicos son controlados por los hombres. Lo demás, afirma, es blando (softnews) y suele ser colocado en la periferia y bajo el análisis de las mujeres. Esta diferenciación no se une a la calidad del producto sino a las temáticas y sus significaciones simbólicas.

Respecto del humor en concreto, fue Lakoff (1975) quien recuerda que durante décadas se socializó a las mujeres en que no era apropiado contar chistes delante de un hombre, y en la exigencia de control humorístico. Por lo tanto, y como en otras áreas de la vida personal o social, las mujeres hemos ido recibiendo una socialización sesgada. Son entendibles, en este contexto, las reflexiones de Isabel Franc, quien subraya que las mujeres siempre han hecho humor pese a (o justo por) los mecanismos represivos que coartan su presencia en el imaginario. En ese sentido, confirma que se ha robado a las mujeres la posibilidad de convertirse en referentes para otras mujeres en esta área. La autora lo expresa así: "cuando digo escasa presencia me refiero a lo poco referenciadas que están, no a que no existan" (Franc, 2017:9).

\section{Breve contextualización sobre Instagram}

Creada para compartir, valorar y comentar imágenes Instagram es, actualmente, la plataforma de visibilidad y lanzadera para muchos perfiles profesionales que tiene como característica fundamental el que genera feed-back inmediato. Como recuerda (Candale, 2017), cuenta con un servicio de mensajería privada como modalidad sincrónica de comunicación y la posibilidad de añadir comentarios a las imágenes, como modalidad asincrónica.

Evidentemente no solo apoya lo profesional, sino que conecta con lo más personal ayudando en el uso compartido de vivencias al alimentar vinculaciones y relaciones interpersonales y al fortalecer las intrapersonales.

Se ha convertido en una de las redes con más tráfico del momento. En 2018 cerró con 2 billones de personas usuarias activas (11 millones de personas usuarias en EEUU, 70 millones en Brasil y 15 millones en España), superando a cualquier otra red social y compartiendo más de 80 millones de imágenes al día (Statista, 2019). Indudablemente, su éxito ha animado a que cada vez más empresas estén dentro de ella.

Fue en abril de 2012 cuando la plataforma pasó a manos de Facebook, lo que supuso duplicar, como poco, la visibilidad del contenido compartido puesto que con un pequeño golpe de clic se enlaza con el perfil de Facebook al que se haya vinculado la cuenta de Instagram. En 2018, como decíamos, ya era la Red social que más había crecido en España alcanzando los quince millones de personas usuarias.

Una de sus características reseñables es que el $70 \%$ de los perfiles corresponden a personas jóvenes con edades que oscilan entre los 18 y los 39 años. Se autoalimenta con calificaciones, algo que se está convirtiendo en significante para la configuración de la identidad personal y social de quienes lo usan. Precisamente la interacción constante es una demanda de las personas jóvenes respecto de las relaciones interpersonales, también cuando éstas están mediadas (online). Su éxito no solo está en la ganancia de seguidores sino en lograr fidelizarlos tanto a las ideas como a los productos que se presentan. En ese sentido, las stories, auténticas e interactivas, ayudan.

\section{Método}

El diseño metodológico elegido se ha sustentado en cuatro fases: A) Elaborar un listado de las mujeres que hacen humor gráfico en España; B) Realizar una búsqueda en Instagram para comprobar si hacen uso de esta red social; C) Una vez conformada la lista de estas mujeres, seleccionar las diez últimas viñetas que han publicado eligiendo un día y una hora concreta, al azar, para la obtención del material; D) Aplicar el análisis de contenido como estrategia metodológica. Ello obliga a elaborar una ficha de análisis ad hoc para evaluar cada viñeta y extraer conclusiones.

Para generar el listado de ilustradoras gráficas, se utilizó en primera instancia el buscador Google Scholar. Las palabras-clave de acceso a artículos científicos fueron: a) Mujeres y humor gráfico en España; b) Mujeres viñetistas; c) Ilustradoras gráficas; d) Prensa y humor, la visión de las 
mujeres. Después de una lectura pormenorizada, se encontraron investigaciones cuyo objeto de estudio es la obra de Maitena Burundarena o de Nuria Pompeia. Al ser tan restrictivo el resultado, se pasa a realizar una búsqueda en Google incluyendo las mismas palabras-clave. En este caso, encontramos una serie de artículos de divulgación científica o reportajes periodísticos que permiten componer tres listados de mujeres que hacen humor gráfico, con coincidencias de nombres en las distintas categorías. Cuando se inicia esta búsqueda en la red social nombrada, encontramos una ilustradora más, Raquel Riba Rossy, que firma como Lola Vendetta, a la que se incluye. Lo mismo ocurre con EsCarolota, cuyos trabajos han sido proyectados y alabados por diferentes medios de comunicación, aunque no se dedica profesionalmente a ello. Resulta un listado inicial de doce nombres.

Una vez elaborado ese listado, se comprueba si mantienen cuenta en Instagram para en el caso de que no sea así, poder descartarlo. Ello significa que se ha hecho compatible un muestreo intencional con uno probabilístico para reducir el sesgo. Como se sabe, el muestreo intencional es una técnica que se utiliza de manera más común dada su sencillez y las posibilidades de accesibilidad para estudiar la muestra.

Deben aclararse dos cuestiones relativas al corpus. Por un lado, se incorpora Es Carolota a la lista de ilustradoras gráficas porque, aunque no se dedica profesionalmente a ello, sí que utiliza en su profesión las viñetas. A la vez, tiene una cantidad de personas que la siguen que la convierte en sujeto de análisis. En 2018 ha publicado el libro titulado "ABC feminista". Por otro, queda descartada de esta selección Diana Raznovich, una ilustradora gráfica de reconocido prestigio en nuestro país y que trabaja como colabora de la "Revista con la A", porque carece de cuenta de Instagram activada. Así pues, el listado final cuenta con once nombres.

Realizada la selección de humoristas e ilustradoras gráficas, se accede al perfil y se extraen diez viñetas por cada una de ella. Se establece como criterio la elección de las diez primeras que aparecen en su perfil el día que entramos en él. Dicha búsqueda se realiza entre el mes de febrero y marzo de 2019. Se genera un corpus de 110 viñetas a las que se aplica una ficha de análisis de contenido.

Tal y como está avalado, el análisis de contenido es una técnica de recogida de información, objetiva y sistemática que permite transformar un documento en una serie de resultados cuantitativos y numéricos. Su finalidad es la de describir de manera objetiva y cuantificable los contenidos manifiestos de una comunicación expresada en algún texto (impreso o audiovisual). Nace y se desarrolla en el siglo XX, asociada a los estudios sobre los Medios de Comunicación (Krippendorff, 1990). Su aplicación pasa por la creación de una ficha de análisis. La correspondiente ficha fue aplicada a cada una de ellas y ha permitido obtener una información cuantitativa además de interpretativa, común y compartible. La ficha contiene tres grandes bloques: I. Identificación del documento (la viñeta); II. Contenido general centrado en el protagonismo y III. Contenido específico que contiene cinco categorías temáticas vinculadas a itinerarios vitales (lo personal, lo interpersonal y lo laboral). A ello se han añadido dos cuestiones que están ancladas, de una manera $\mathrm{u}$ otra, a esos itinerarios vitales (conceptos psicosociales y conceptos ideológicos). Las categorías específicas se reflejan en las siguientes: a) El ámbito personal: El cuerpo/El estado de ánimo; b) el ámbito interpersonal; c) el ámbito laboral, d) conceptos ideológicos y e) conceptos psicosociales. Cada una de estas categorías, se subdividen en otras categorías específicas convenientemente definidas para evitar errores de adjudicación. El sistema categorial específico ha permitido gestionar los datos cualitativos.

El tratamiento de los resultados supone la inferencia y la interpretación. En esta última fase se extraen los datos útiles para el proceso de explotación del material, y para la verificación de los objetivos planteados previamente. "Operaciones estadísticas simples (porcentajes) o más complejas (análisis factorial) permiten establecer cuadros de resultados, diagramas, figuras, modelos que condensan y ponen en relieve las informaciones aportadas por el análisis" (Bardin, 1986:76). 
Tabla 1. Ficha de análisis de contenido

\begin{tabular}{|l|l|l|}
\hline \multicolumn{2}{|c|}{ I. IDENTIFICACION DEL DOCUMENTO } \\
\hline 1. $\mathrm{N}^{\circ}$ y Quién & Número de viñeta y autora \\
\hline 2. Texto & & Incluir texto \\
\hline 3. @/\# & & Número de @/\# incluidos \\
\hline 4. $\mathrm{N}^{\circ}$ likes & Número de likes de la foto \\
\hline $5 . \mathrm{N}^{\circ}$ comentarios & & Número de comentarios a laviñeta \\
\hline 6. Fecha/hora & Fecha de publicación \\
\hline
\end{tabular}

\begin{tabular}{|l|l|l|}
\hline \multicolumn{2}{|c|}{ II. CONTENIDO GENERAL } \\
\hline Variable & Categorías & \\
\hline \multirow{3}{*}{ 7. Protagonismo } & Mujeres & \\
\cline { 2 - 3 } & Hombres & \\
\cline { 2 - 3 } & Otros géneros & \\
\cline { 2 - 3 } & La misma autora & \\
\hline
\end{tabular}

\begin{tabular}{|c|c|c|}
\hline \multicolumn{3}{|c|}{ III. CONTENIDO ESPECÍFICO } \\
\hline Variable & Categorías & Definición \\
\hline \multirow{4}{*}{$\begin{array}{l}\text { 8. Ámbito personal: El } \\
\text { cuerpo }\end{array}$} & Cosmética & $\begin{array}{l}\text { Se atiende a cuestiones relacionadas con productos o ideas } \\
\text { que ayudan a preservar o embellecer partes o la totalidade } \\
\text { del cuerpo. Se incluyen ideas relacionadas con } \\
\text { especialidades médicas destinadas al cuidado del cuerpo: } \\
\text { cirugía estética, plástica o dermatológica. }\end{array}$ \\
\hline & Alimentación & $\begin{array}{l}\text { Se atiende a cuestiones vinculadas ala ingesta de alimento } \\
\text { y sus consecuencias en el aspecto físico. }\end{array}$ \\
\hline & Estética & $\begin{array}{l}\text { Se atiende a cuestiones vinculadas a la belleza y gira en } \\
\text { torno a la percepción de lo bello. }\end{array}$ \\
\hline & Otras & $\begin{array}{l}\text { Espacio para incluir otras cuestiones que afecten al cuidado } \\
\text { o la percepción del cuerpo inicialmente no contempladas. }\end{array}$ \\
\hline \multirow{5}{*}{$\begin{array}{l}\text { 9. Ámbitopersonal/ } \\
\text { interper-sonal }\end{array}$} & Sexo & $\begin{array}{l}\text { Se atiende a cuestiones relacionadas con la sexualidad: } \\
\text { prácticas sexuales, orientación sexual. }\end{array}$ \\
\hline & Amor & Se atiende a cuestiones vinculadas al cariño, al afecto. \\
\hline & Amistad & Se atiende a cuestiones relacionadas con la amistad. \\
\hline & $\begin{array}{l}\text { Cuidado } \\
\text { familia }\end{array}$ & $\begin{array}{l}\text { Se atiende a cuestiones relacionadas con la responsabilidad } \\
\text { y el cargo de hijas/os, personas mayores, etc. }\end{array}$ \\
\hline & Otro & $\begin{array}{l}\text { Espacio para incluir otras cuestiones inicialmente no } \\
\text { contempladas }\end{array}$ \\
\hline \multirow{5}{*}{$\begin{array}{l}\text { 10. Ámbito personal: } \\
\text { Estado de ánimo }\end{array}$} & Cansancio & Fatigado. \\
\hline & Alegría & $\begin{array}{l}\text { Emoción de júbilo que puede expresarse a través de } \\
\text { palavras o gestos. }\end{array}$ \\
\hline & Ironía & $\begin{array}{l}\text { Como figura retórica permite expresar una cosa diciendo la } \\
\text { contraria. }\end{array}$ \\
\hline & Enojo & Expresa disgusto. \\
\hline & Otro & Espacio para incluir otros inicialmente no contemplados \\
\hline \multirow[t]{2}{*}{ 11. Ámbito laboral } & $\begin{array}{l}\text { Formación para } \\
\text { el empleo }\end{array}$ & $\begin{array}{l}\text { Conjunto de instrumentos y acciones que proporciona a las } \\
\text { empresas y a trabajadoras/es ocupados y desempleados, } \\
\text { un adiestramiento adecuado a sus necesidades y a las del } \\
\text { mercado de trabajo. }\end{array}$ \\
\hline & Trabajo & $\begin{array}{l}\text { Actividades que son realizadas con el objetivo de alcanzar } \\
\text { una meta, solucionar un problema o producir bienes y } \\
\text { servicios para atender las necesidades humanas. }\end{array}$ \\
\hline 12. Nociones ideológicas & Feminismo & $\begin{array}{l}\text { Movimiento político-social que supone la toma de } \\
\text { conciencia de la dominación de la que han sido objeto las } \\
\text { mujeres por parte de los varones en el seno del patriarcado } \\
\text { y que promueve acciones para el cambio. }\end{array}$ \\
\hline
\end{tabular}




\begin{tabular}{|c|c|c|}
\hline & Libertad & $\begin{array}{l}\text { Facultad y derecho de las personas para elegir de manera } \\
\text { responsable su forma de actuar en sociedad. }\end{array}$ \\
\hline & Diversidad & $\begin{array}{l}\text { Se refiere a la diferencia o a la distinción entre personas, } \\
\text { animales o cosas, a la variedad, a la infinidad o a la } \\
\text { abundancia de cosas diferentes, a la desemejanza, a la } \\
\text { disparidad o a la multiplicidad. }\end{array}$ \\
\hline & Otra & Espacio para incluir otras cuestiones \\
\hline \multirow{4}{*}{$\begin{array}{l}\text { 13. Conceptos } \\
\text { psicosociales }\end{array}$} & Autoestima & Valoración, generalmente positiva, de sí misma \\
\hline & Autonomía moral & $\begin{array}{l}\text { Capacidad de poder tomar decisiones aplicando la ley de } \\
\text { moralidade propia, voluntaria, auto-consciente, } \\
\text { independiente y libre de influencias o intervenciones } \\
\text { interpersonales. }\end{array}$ \\
\hline & $\begin{array}{l}\text { Inteligencia } \\
\text { emocional }\end{array}$ & $\begin{array}{l}\text { Capacidad para reconocer y manejar adecuadamente los } \\
\text { sentimentos propios y ajenos. }\end{array}$ \\
\hline & Otro & $\begin{array}{l}\text { Espacio para incluir otras cuestiones inicialmente no } \\
\text { contempladas }\end{array}$ \\
\hline
\end{tabular}

Elaboración propia.

\section{Presentación de resultados y discusión}

Tras examinar el corpus de datos reunidos, puede señalarse que en la segunda década de siglo XXI están haciendo humor gráfico en el contexto español once mujeres. En la tabla siguiente se las nombra junto a su filiación y algunas notas curriculares:

Tabla 2. Listado de ilustradoras gráficas españolas

\begin{tabular}{|c|c|c|c|}
\hline Nombre & Firma & Notas biográficas & $\begin{array}{c}\text { Seguimiento en } \\
\text { Instagram } \\
(19 / 04 / 2019) \\
\end{array}$ \\
\hline Raquel Córcoles & $\begin{array}{c}\text { Moderna de } \\
\text { Pueblo }\end{array}$ & $\begin{array}{l}\text { Licenciada en Periodismo. Ilustradora y } \\
\text { autora de cómics. Ha publicado en el } \\
\text { semanário El Jueves, en la revista Cuore, } \\
\text { además de en El Estafador. Ha escrito varias } \\
\text { novelas gráficas, en las que se encuentra, por } \\
\text { ejemplo, la titulada Idiotizadas. De cuentos } \\
\text { de hadas a empoderadas, que se publica en } \\
\text { 2017. Después de algunos años en los que } \\
\text { ha tenido que compatibilizar el dibujo con } \\
\text { otros trabajos, ha conseguido dedicarse en } \\
\text { exclusiva a sus viñetas. }\end{array}$ & 1.165 .598 \\
\hline Flavia Álvarez & Flavita Banana & $\begin{array}{l}\text { Ilustradora formada en Arte y Diseño. Sus } \\
\text { trabajos aparecen en el diario español de } \\
\text { tirada nacional El País o en el semanário } \\
\text { Mongolia. Ha escrito vários libros, uno de } \\
\text { ellos se titula Las cosas del querer (2017). En } \\
\text { el año } 2018 \text { obtiene el Premio Internacional } \\
\text { de Humor GatPerich }\end{array}$ & 496.729 \\
\hline Agustina Guerrero & La volátil & $\begin{array}{l}\text { Ilustradora argentina afincada en Barcelona. } \\
\text { Creadora de El diario de una volátil a través } \\
\text { del cual "pinta" situaciones cotidianas dando } \\
\text { voz a las mujeres. Ha publicado vários libros, } \\
\text { uno de ellos titulado Érase una vez la volátil, } \\
\text { que publica en 2016, traducido a varias } \\
\text { lenguas. }\end{array}$ & 492.572 \\
\hline
\end{tabular}




\begin{tabular}{|c|c|c|c|}
\hline $\begin{array}{l}\text { María Murnen y } \\
\text { Helen Sotillo }\end{array}$ & $\begin{array}{l}\text { Feminista } \\
\text { Ilustrada }\end{array}$ & $\begin{array}{l}\text { María Murnen está licenciada en } \\
\text { Comunicación Audiovisual y ha realizado el } \\
\text { Máster en Género, identidad y ciudadanía. } \\
\text { Diseña y ejecuta campañas sobre igualdad } \\
\text { de género y es docente en diferentes cursos } \\
\text { de formación feminista. } \\
\text { Helen Sotillo es Directora de arte y } \\
\text { Diseñadora gráfica e ilustradora. } \\
\text { Firmando como Feminista ilustrada han } \\
\text { publicado varios libros. }\end{array}$ & 411.775 \\
\hline $\begin{array}{l}\text { Raquel Riba } \\
\text { Rossy }\end{array}$ & Lola Vendetta & $\begin{array}{l}\text { Dibujante e ilustradora graduada en Bellas } \\
\text { Artes. Conferenciante y autora del libro Lola } \\
\text { Vendetta. Más vale Lola que mal } \\
\text { acompañada, editado en } 2017 \text {. }\end{array}$ & 390.170 \\
\hline Estefi Martínez & Pedrita Parker & $\begin{array}{l}\text { Ilustradora y diseñadora. Licenciada en } \\
\text { Periodismo y Máster en Comunicación. } \\
\text { Asesora creativa para marcas como IKEA, } \\
\text { Movistar y Coca-cola. Ha publicado } \\
\text { diferentes libros imparte conferencias. Uno } \\
\text { de los últimos lo titula No eres tú, soy yo, y } \\
\text { se edita en 2017. }\end{array}$ & 172.693 \\
\hline $\begin{array}{c}\text { Anastasia } \\
\text { Bengoechea }\end{array}$ & $\begin{array}{l}\text { Monstruo } \\
\text { Espagueti }\end{array}$ & $\begin{array}{l}\text { Se auto-reconoce como humorista gráfica } \\
\text { licenciada en Publicidad. Autora de vários } \\
\text { libros. En } 2015 \text { publica su primer libro. Su } \\
\text { segundo libro lo titula Estás fatal. }\end{array}$ & 134.291 \\
\hline \multirow[t]{2}{*}{$\begin{array}{c}\text { Maitena Inés } \\
\text { Burundarena } \\
\text { Streb }\end{array}$} & Maitena & $\begin{array}{l}\text { Ilustradora gráfica y guionista de televisión. } \\
\text { Sus trabajos se han publicado durante vários } \\
\text { años en El País Semanal; también en } \\
\text { diferentes diários internacionales como La } \\
\text { Nación. Autora de más de una decena de } \\
\text { libros. Uno de ellos es el titulado Mujeres } \\
\text { alteradas. } \\
\text { Ha sido la primera mujer en obtener La } \\
\text { Catrina, premio que otorga la Feria del Libro } \\
\text { de Guadalajara (México) a dibujantes de } \\
\text { humor gráfico. Lo obtiene en el año } 2013 \text {. }\end{array}$ & 128.097 \\
\hline & Es Carolota & $\begin{array}{l}\text { Profesora de estudiantes en situación de } \\
\text { desventaja social. Se define como } \\
\text { trabajadora precaria aficionada al dibujo a } \\
\text { través del cual expressa algunos } \\
\text { fundamentos del feminismo. Con ese } \\
\text { argumento crea un diccionario feminista } \\
\text { ilustrado. }\end{array}$ & 50.873 \\
\hline Laura Mesa Cusso & Chica del montón & $\begin{array}{l}\text { Ilustradora graduada en Comunicación e } \\
\text { Industrias Culturales. Trabaja en el marketing } \\
\text { digital. Autora del libro Chica del montón, } \\
\text { editado en } 2018 \text {. }\end{array}$ & 47.738 \\
\hline $\begin{array}{c}\text { Laura Pacheco } \\
\text { Torres }\end{array}$ & Let's Pacheco & $\begin{array}{l}\text { Ilustradora, bloguera e historiadora } \\
\text { licenciada en Bellas Artes. Ha trabajado en el } \\
\text { ámbito de las webcómic. Ha trabajado para } \\
\text { la revista } S \text { Moda del diário El País. En estos } \\
\text { momentos lo compatibiliza con trabajos } \\
\text { sobre papel. Su trabajo Problemas del primer } \\
\text { mundo ha sido traducido al francés. }\end{array}$ & 26.028 \\
\hline
\end{tabular}

Elaboración propia. 
Hay que destacar que el seguimiento que reciben tanto Moderna de Pueblo, con más de un millón de personas, como Flavita Banana o La volátil, con casi quinientos mil seguidores cada una, resultan datos interesantes especialmente si se comparan con el dibujante e historietista El Roto (diario El País) que, aunque tiene abierta una cuenta en Instagram, solo cuenta con 2.213 seguidores. Es fácil suponer, conociendo su prestigio y la penetración que tienen en el imaginario colectivo las viñetas del dibujante mencionado que no utiliza este medio especialmente. De otros ilustradores y/o humoristas gráficos como Esteban (La Razón) o José Ma Nieto (diario $A B C$ ) no encontramos perfil abierto en Instagram aunque sí lo tienen en Twitter.

Resulta significativo que todas se reconozcan en la Red, se sigan y se aplaudan entre ellas con likes. Es una buena estrategia de sororidad ${ }^{4}$. Algo que EsCarolota practica doblemente porque sus viñetas son una reinterpretación de las ilustraciones de otras ilustradoras a quien se encarga de citar en una tarea de amplificación de sus trabajos.

¿Quién protagoniza las viñetas que firman estas ilustradoras gráficas? En el $77,1 \%$ de las ocasiones, las viñetas son protagonizadas por mujeres. Son ellas las que ponen la voz y hacen la crítica respecto de temas ideológicos: sociales, económicos o laborales. Dos de las autoras utilizan dibujos autorreferenciales, el resto presentan a mujeres diversas. En cualquier caso, todas hablan de mujeres a las que les pasan cosas parecidas, reconocibles.

\section{Temáticas y controversias}

¿Cuáles son las áreas temáticas más tratadas? El análisis de sus producciones permite afirmar que las ilustradoras tratan de manera recurrente dos categorías temáticas: nociones ideológicas (ocupando el $62 \%$ de las viñetas) y conceptos psicosociales (ocupando el 24,5\%). Dentro de las ideológicas, dan relevancia a la definición de feminismo o subrayan el respeto a la diversidad. Apuestan por la libertad, reniegan de los mandatos patriarcales y del control capitalista sobre el cuerpo de las mujeres o ponen el foco sobre lo que suponen los micromachismos y el mito del amor romántico, por ejemplo. Otra gran área de interés mostrado a través de sus viñetas son los conceptos psicosociales. Las ilustradoras gráficas reflexionan sobre cuestiones vinculadas al autoconcepto, la autoestima o a la inteligencia emocional de las mujeres.

Aunque estos que exponemos son los grandes ejes, también se vierten críticas sobre cuestiones laborales donde incluyen las dificultades en el acceso y promoción laboral o el acoso. Igualmente plantean cuestiones vinculadas a las relaciones interpersonales, estando presentes temas como el deseo sexual o el cuidado de la familia y la personales como la masturbación.

Moderna de pueblo focaliza su reflexión en las nociones ideológicas, que supone el $80 \%$ del total del contenido de las viñetas analizadas. La que promueve más reacciones en quien la sigue en Instagram es una vinculada a la defensa de la diversidad unida a la imposición de una estética corporal determinada. Se posiciona frente a esos mandatos patriarcales que exigen que el cuerpo de las mujeres tenga unas determinadas proporciones. Obtiene 167.412 likes.

\footnotetext{
4 El término sororidad ha sido incluído en la Real Academia de la Lengua Española en 2018. Procede del latín (sororitas) y se puede traducir como "hermanar". Marcela Lagarde ya usaba el término en 1997 para nombrar el pacto simbólico que firman muchas mujeres para contrarrestar la brecha social existente defendiendo que a pesar de que es a los hombres y no a las mujeres a los que naturalmente se les entrena para aliarse, las propias mujeres pueden hacerlo con unos interesantes resultados que se pueden medir en términos de interés de los proyectos o en la pertinencia y potencia de los mismos.
} 
Viñeta 1. Autora: Flavita Banana. Se publica el 06/02/2019



Flavita Banana también pone en el centro de su reflexión las nociones ideológicas, que suponen un $50 \%$ del total del contenido de las viñetas analizadas. Incluye un análisis crítico sobre algunas insanas relaciones laborales. La que promueve más reacciones en quien la sigue en Instagram es una vinculada a la definición de feminismo como reacción a quienes intentan inducir a error a las personas más jóvenes o menos formadas. Obtiene 78.493 likes.

La volátil pone el foco de su interés en los conceptos psicosociales, que suponen el $50 \%$ del total del contenido de las viñetas analizadas. La que promueve más reacciones en quien la sigue en Instagram es una vinculada al autoconcepto de las mujeres, ese que hay que fortalecer. Obtiene 39.405 likes.

Feminista Ilustrada utiliza como hilo argumental las nociones ideológicas. La viñeta que acumula más reacciones en Instagram une mandatos patriarcales con control capitalista y cómo ambos actúan proyectando un ideal de estética corporal femenina. Recibe 37.164 likes.

Lola Vendetta se centra en las nociones ideológicas, que suponen un $70 \%$ del contenido total tratado en las viñetas analizadas. La que obtiene más interacciones en Instagram es una vinculada a la sororidad. Obtiene 36.338 likes.

Pedrita Parker coloca en el centro de su crítica las nociones ideológicas, que suponen un $70 \%$ del total del contenido de las viñetas analizadas. La que promueve más reacciones en quien la sigue en Instagram es una que cuestiona el sentido de la libertad, que queda en entredicho cuando se une al mundo laboral y a la sobrecualificación. Obtiene 9.517 likes.

Viñeta 2. Autora: Monstruo espagueti. Se publica el 31/01/ 2019

$$
\begin{aligned}
& \text { COMO } \\
& \text { TANTO BIO } \\
& \text { QUEME } \\
& \text { SALE TOFV } \\
& \text { DEL HIOO }
\end{aligned}
$$

mo unero

Monstruo Espagueti pone como centro de su interés temático las nociones ideológicas, que suponen un $60 \%$ del total del contenido de las viñetas analizadas. La que promueve más reacciones 
en quien la sigue en Instagram es una que une los mandatos patriarcales a las relaciones laborales. Obtiene 18.577 likes.

Maitena focaliza su interés en los conceptos ideológicos, que suponen un $70 \%$ del total de los contenidos que trata en las viñetas evaluadas. La que promueve más reacciones en quien la sigue en Instagram une mandatos patriarcales con la proyección y exigencia de mantener el cuerpo de la mujer siguiendo unos cánones restrictivos.

EsCarolota utiliza como hilo argumental los conceptos ideológicos. La viñeta que promueve más reacciones en Instagram es una que habla de algo que es natural para las mujeres, aunque ha sido desnaturalizado por los mandatos patriarcales. Habla de la menstruación y recibe 12.530 likes.

Chica del montón, aunque incorpora tres tipos de temáticas en las viñetas estudiadas, sí que predominan las que aluden a las nociones ideológicas, que suponen un $50 \%$ del total. La viñeta que promueve más reacciones en Instagram es una que une el concepto de diversidad con las cuestiones relativas al cuerpo de las mujeres. Obtiene 4.733 likes.

Let's Pacheco es la única que plantea un equilibrio temático y trata todos los asuntos que hemos categorizado. Es verdad que tanto los conceptos ideológicos como los psicosociales tienen un poco más de peso que el resto (el cuerpo, el ámbito laboral y el interpersonal). De todas formas, la viñeta que recibe más likes (2.091) une mandatos patriarcales con exigencias para las mujeres de mantener un cuerpo con una estética muy determinada junto con una alimentación muy constreñida.

De las once ilustradoras gráficas, seis abordan el tema del cuerpo de las mujeres vinculándolo a mandatos patriarcales. Una mirada feminista que se ancla a situaciones históricas que hay que deslegitimar y revertir. Cierto es que a lo largo del tiempo a las mujeres se les ha marcado no solo cómo deben ser sino cómo deben estar: se les ha indicado cómo han de comportarse y cómo tienen que mantener un cuerpo que, por lo visto, no les pertenece. El cuerpo de las mujeres ha recibido, y recibe, mandatos sociales muy concretos; para ser querida, para ser respetada... se han de acatar las normas. Resultan definitivas las palabras de Morcillo Gómez cuando afirma que "los cuerpos de las mujeres son a un tiempo organismos físicos reales y receptáculos de las convenciones culturales que históricamente les ha marcado bajo el rótulo de la feminidad" (Morcillo Gómez, 2015:11). Se llega a un punto en el que las mujeres no se sienten dueñas de su cuerpo porque se aprecian en función del "otro" (la pareja, el espejo, los cánones de belleza). De hecho, y como constata Freixas (2018), a partir de una determinada edad "las mujeres se sienten legitimadas para hablar de su cuerpo en función de la enfermedad y no en relación al placer" (2018:32). Estas afirmaciones son algunas de las que nos han ayudado a delimitar la categoría conceptos ideológicos. En definitiva, puede afirmarse que el cuerpo de las mujeres está ideologizado y recibe exigencias de lo que debe y no debe ser; de cómo debe y no debe estar.

Reconocemos que el término ideología está intrínsecamente unido al de ideas. En este sentido, nos parecen determinantes las palabras de van Dijk (2005) al definirla como "el fundamento de las representaciones sociales compartidas por un grupo social". Además, este mismo autor añade que "[...]También los grupos dominados pueden tener ideologías, a saber, las ideologías de la resistencia y oposición" (van Dijk, 2005:17). Esto es lo que encontramos en un alto porcentaje de las viñetas analizadas porque hacen propuestas desde la resistencia para promover el cambio social. Puede hacerse una extrapolación de esas reflexiones que Morduchowicz (2003) realiza sobre los medios de comunicación en general y sobre el cine en particular, entendiéndolos como verdaderas pedagogías públicas, y afirmamos que las viñetas son pedagógicas teniendo la posibilidad de movilizar las actitudes a nivel cognitivo cuestionando lo que se piensa, a nivel emocional removiendo lo que se siente y a nivel comportamental activando la acción (lo que se hace) en un sentido determinado. No se debe olvidar que la movilización social ha conseguido el cambio de normativas y leyes. 
Viñeta 3. Autora: Moderna de Pueblo. Se publica el 07/03/ 2019

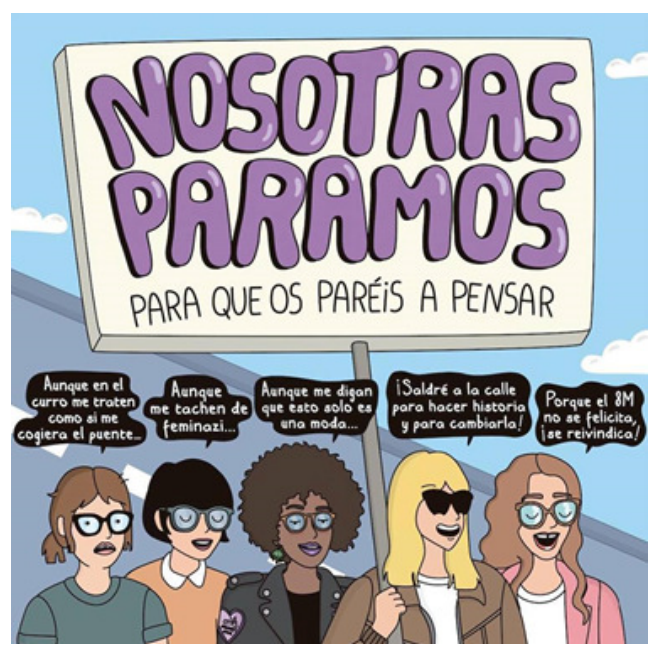

\section{4 de febrero y 8 de marzo, ¿qué decir?}

Se concreta el análisis en dos fechas específicas por su simbolismo: el 14 de febrero ${ }^{5}$ y el 8 de marzo. Diez de las once ilustradoras gráficas dedican sus viñetas a temas relacionados con el amor (14 de febrero) y con las reivindicaciones del 8 de marzo.

Moderna de Pueblo, Flavita Banana, La volátil, Feminista Ilustrada, Lola Vendetta, Monstruo Espaguetti, Pedrita Parker, Chica del montón o Let's Pacheco hacen una viñeta alusiva al 14 de febrero. Estas nueve viñetas analizadas se pueden dividir en dos tipos de mirada: aquellas que vienen a desmotar el mito del amor romántico explícitamente y aquellas que enfatizan el autocuidado, la autoestima, la voluntad de acción de quererse a una misma. Así pues, se entrelazan los conceptos ideológicos y los conceptos psicosociales. Por ejemplo, en la viñeta de Pedrita Parker que se publica el 13 de febrero encontramos a una mujer joven delante de un espejo. El texto que acompaña al dibujo dice: "Nunca dejes de enamorarte de la persona que te mira desde el espejo". En la misma línea, Lola Vendetta firma una viñeta el 14 de febrero que contiene un dibujo de una joven delante de un espejo del baño y que es acompañado por el siguiente texto: "Cariño, no creo que nadie nunca te quiera tanto como te quiero yo". En ambos casos, la llamada a la autoestima conlleva empoderamiento.

\footnotetext{
${ }^{5}$ En esta fecha se celebra el "Día de los enamorados" en conmemoración de San Valentín. Es una festividad de origen cristiano que está relacionada con el concepto universal del amor y la afectividad. En el año 2015, feministas chilenas inician una campaña para hacer visibles las desventajas del amor idealizado que implica subordinación, dependencia y abnegación. En España, ese mismo año, un grupo de feministas plantea una campaña en idéntico sentido.
} 
Viñeta 4. Autora: Lola Vendetta. Se publica el 14/02/ 2019

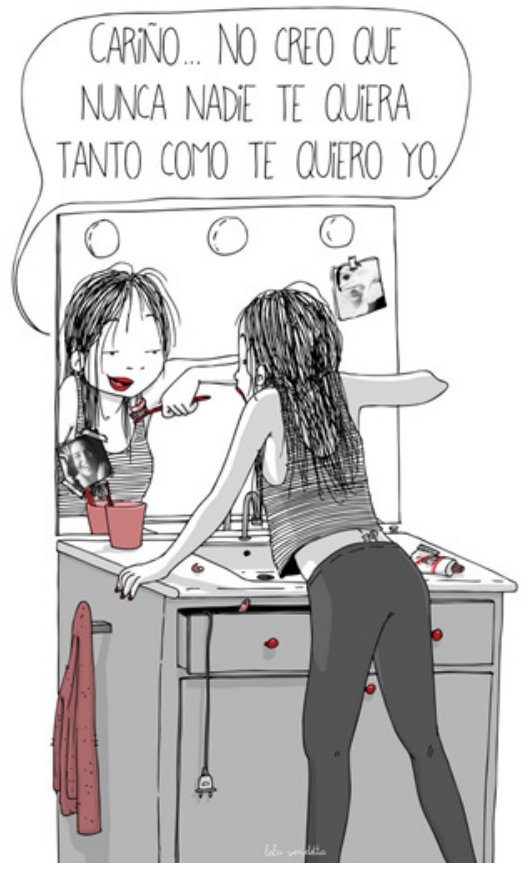

Respecto del 8 de marzo, todas las ilustradoras representan nociones ideológicas y, unánimemente, se decantan por publicarlas el día previo (7 de marzo) como preludio a las reivindicaciones y para respetar la convocatoria de paro. Por ejemplo, la viñeta de Feminista Ilustrada contiene el siguiente texto: "8 de marzo, día de las mujeres. Este no es un día para: - poner descuentos a las mujeres, - hacer fiestas temáticas, - promocionar tu negocio. Es un día para reivindicar. El capitalismo no se va a apoderar de nuestra lucha". Obtiene 46.869 likes. Moderna de pueblo representa a cinco mujeres diversas. Una de ellas porta una pancarta con el siguiente texto: "Nosotras paramos para que no paréis de pensar". Y cada una dice: (1) "Aunque en el curro me traten como si cogiera el puente", (2) "Aunque me tachen de feminazi", (3) "Aunque me digan que esto es solo una moda", (4) "Saldré a la calle para hacer historia y para cambiarla", (5) "Porque el $8 \mathrm{M}$ no se felicita, se reivindica". Obtiene 117.055 likes.

\section{Algunas conclusiones}

El feminismo de la cuarta ola, ese que posibilita el activismo online usando como mediadoras a las redes sociales, ha conseguido sumar a jóvenes y ha posibilitado el encuentro de muchas feministas en un diálogo intergeneracional que es muy significativo a nivel táctico y a nivel estratégico. En esto, Instagram tiene un especial potencial vinculado a la estética de los discursos y al propio lenguaje.

Otra de las conclusiones que se puede extraer después de valorar los resultados, es que las ilustradoras gráficas que trabajan en el territorio español y que muestran sus propuestas a través de Instragram optan por una resignificación política de lo femenino. Trascienden de las informaciones blandas para comprometerse ideológicamente y promover cambios sociales. Toman la esfera pública con el afán de convertirse en altavoces que permitan remover lo social. Por ese motivo consideramos que hacen arte activista, tal como lo entienden Aznar Almazán e Íñigo Clavo (2007), siendo capaces de estimular el sentido crítico y el sentido político. Y están muy en consonancia con lo que Miyares (2018) plantea sobre temáticas que tienen que ver con la agenda inconclusa de la paridad; una agenda que incorpora violencias sutiles, como el acoso o la explotación sexual.

Por su parte, la autogestión a través de la Red Instagram, permite esquivar el techo de cristal que las empresas periodísticas imponen. Sin embargo, este cambio de ruta abre otras vías que precisan un abordaje posterior. La potencialidad de las redes sociales para amplificar y extender el repertorio de significados y prácticas, nos recuerda que estas identidades públicas, las de las viñetistas y sus discursos, siempre se construyen en relación dialógica con sus públicos. Las 
reacciones, los likes, ya nos están exigiendo mutar el punto de vista para interesarnos por ese espacio público ampliado donde coexisten sujetos, discursos y colectivos.

\section{Referencias bibliográficas}

ARAÜNA, Núria; WILLEM, Cilia y TORTAJADA, Iolanda. Discursos feministas y vídeos de youtubers: límites y horizontes de la politización yo-céntrica. Quaderns del CAC (45). 2019, pp.25-35. [https://www.cac.cat/sites/default/files/2019-09/Q45_ES_0.pdf].

AZNAR ALMAZÁN, Yayo e ÍNIIGO CLAVO, María. Arte, política y activismo. Concinnitas (1)10, 2007, pp.6577 [https://www.e-publicacoes.uerj.br/index.php/concinnitas/article/viewFile/22888/16325]

BALLESTEROS DONCEL, Esmeralda. Circulación de memes en WhatsApp: ambivalencias del humor desde la perspectiva de género. EMPIRIA. Revista de metodología en Ciencias sociales (35), 2016, pp.21-45 [https://eprints.ucm.es/id/eprint/39283/1/EMPIRIA_2016.pdf].

BARDIN, Laurence. Análisis de contenido. Barcelona, Akal, 1986.

BARRERO, Manuel. El Jueves: revista de la transición, revista en transición. Tebeosfera, cultura gráfica [http://www.tebeosfera.com/obras/documentos/el_jueves_revista_de_la_transicion_revista_en_transicion.ht $\mathrm{ml}$ - acceso el 1 de febrero de 2020].

CANDALE, Carmen Valentina. Las características de las redes sociales y las posibilidades de expresión abiertas por ellas. La comunicación de los jóvenes españoles en Facebook, Twitter e Instagram. Colindancias, Revista de la Red de Hispanistas de Europa Central, 8, 2017, pp.201-218 [https://dialnet.unirioja.es/servlet/articulo?codigo=6319192].

CAPDEVILA, Jaume (comp.). Si los curas y frailes supieran. Barcelona, Ediciones La tempestad, 2010.

CARRETERO DIOS, Hugo; PÉREZ MELÉNDEZ, Cristino y BUELA CASAL, Guadalberto. Dimensiones de la $\begin{array}{llllll}\text { apreciación del humor. } & \text { Psicothema } & \text { (18)3, 2006, } & \text { pp. }\end{array}$ [http://www.psicothema.com/psicothema.asp?id=3239].

COHEN, Bernard Cecil. The Press and the Foreign Policy. Princenton, UniversityPress, 1963.

FAGOAGA, Concha. Lo duro y lo blando: cambios en la tipificación de la noticia. En: ABRIL, Natividad (coord.). Género, sexo, medios de comunicación. Realidades, estrategias, utopías. País Vasco, Emakunde, 2004, pp.117-124.

FRANC, Isabel (ed.). Las humoristas. Ensayo poco serio sobre mujeres y humor. Barcelona, Icaria, 2017.

FREIXAS, Anna. Sin reglas. Erótica y libertad femenina en la madurez. Madrid, Capitan Swing, 2018.

FLÜGEL, John Carl. Humor and laughter. En: GARDNER, Lindzey (ed.). Handbook of social psychology (2), Cambridge, Mass Addison-Wesley, 1954, pp.709-734.

FUERTES, Gloria. Con alegría. Antología. 50 años de poesía. Madrid, Escuela Española, 1991.

GERBNER, George. Cultivation Analysis: An overview. Mass Communication \& Society (1), 1998, pp.175194 [https://doi.org/10.1080/15205436.1998.9677855].

GUILLAMET, Jaume. Conocer la prensa. Barcelona, Gustavo Gili, 1988.

JÁUREGUI, Eduardo. El sentido del humor. Barcelona, Integral, 2007.

JUSZKO, Paulina. El humor de las argentinas. Buenos Aires, Editorial Biblos, 2000.

KRIPPENDORF, Klaus. Metodología de análisis de contenido: teorías y prácticas. Barcelona, Paidós, 1990.

LAGUNA PLATERO, Antonio; MELÉNDEZ MALAVÉ, Natalia; BARRERO, Manuel. La risa periodística. Teoría, metodología e investigación en comunicación satírica. Valencia, Tirant lo Blanch, 2010.

LAKOFF, Robin. Language and Woman's Place. Nueva York, Harper Colophom, 1975.

MARTINEZ, Fabiana. Feminismos em movimento no ciberespaço. cadernos pagu (56), Campinas, SP, Núcleo de Estudos de Gênero-Pagu/Unicamp, 2019 [http://dx.doi.org/10.1590/18094449201900560012].

MCCOMBS, Maxwell E.; SHAW, Donald L. The Evolution of Agenda-Setting Research: Twenty-Five Years in the Marketplace of Ideas. Journal of Communication (43)2, 1993, pp.58-67 [https://doi.org/10.1111/j.1460-2466.1993.tb01262.x]. 
MIYARES, Alicia. La cuarta ola del feminismo, su agenda. 2018 [https://tribunafeminista.elplural.com/2018/03/la-cuarta-ola-del-feminismo-su-agenda/ - acceso el 1 de febrero de 2020].

MONJE, M Milar. El humor en la poesía de Gloria Fuertes. Tarragona, Universitat Rovira i Virgili, 2007 [https://www.tdx.cat/handle/10803/8782\#page $=1$ - acceso el 8 de agosto de 2020].

MORCILLO GÓMEZ, Aurora. En cuerpo y alma. Ser mujer en tiempos de Franco. Madrid, Siglo XXI, 2015.

MORDUCHOWICZ, Roxana. El sentido de una educación en medios. Revista Ibero-Americana de Educação (32), 2003, pp.35-47 [https://rieoei.org/historico/documentos/rie32a02.pdf].

NÚÑEZ DOMÍNGUEZ, Trinidad. Viñetas y socialización. IC. Revista Científica de Información y Comunicación (12), 2015, pp.203-226 [http://hdl.handle.net/11441/33064]. 23.

¿Las mujeres generan opinión? Observatorio. Medios de Comunicación y Sociedad (10), 2011, pp.8-

SEGADO-BOJ, Francisco. Un tópico perpetuado. La imagen de la mujer y el feminismo en el humor gráfico de la prensa diaria durante la transición. Zer (14) 27, 2009, pp.203-224 [https://doi.org/10.1387/zer.2412].

STATISTA. Ranking de países con mayor número de usuarios de Instagram a nivel mundial en julio de 2018 [https://es.statista.com/estadisticas/875291/paises-con-mayor-numero-de-usuarios-de-intagram - acceso el 1 febrero 2020].

TWAIN, Mark. Las aventuras de Tom Sawyer. Alicante, Biblioteca Virtual Cervantes, 2005 [http://www.cervantesvirtual.com/obra-visor/las-aventuras-de-tom-sawyer--0/html/0005943c-82b2-11dfacc7-002185ce6064_5.html - acceso el 1 de febrero de 2020].

VALERO GARCÉS, Carmen. Humor, mujeres y cultura. Algo sobre cómo reírse con y de las mujeres. Dossier feministes (8), 2005, pp.153-184.

VAN DIJK, Teun A. Política, ideología y discurso. Quórum Académico (2) 2, 2005, pp.15-47. [https://www.consensocivico.com.ar/documento/2277-van-dijkteun-a-politica-ideologia-y-discurso/]. 